\title{
A Case Study of Home-school Cooperation for High Risk Students in Long Tracking
}

\author{
Ling Yan, ${ }^{\mathrm{a}, *}$, and Zhengjun Wang ${ }^{\mathrm{b}}$ \\ The College of Post and Telecommunication of WIT, Wuhan, China

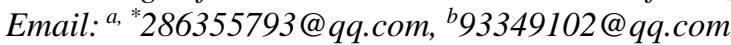

\begin{abstract}
ABSRTACT
Home-school cooperation plays an important role in the psychological precision support in colleges and universities. This paper will reveal a case study of home-school cooperation for high risk students in long tracking. In the process of crisis intervention, the practical dilemma of home-school cooperation should be paid attention to without break. Home-school cooperation should be vigilant. Only by keeping communication open, can the probability of parents old state rekindling and carelessness be reduced.
\end{abstract}

Keywords: Home-school cooperation, High risk students, Psychological, Long tracking.

\section{CASE DESCRIPTION}

Here is a real case in recent years. The party has been named $\mathrm{MO}$, in order to protect the privacy.

MO, male, 20 years old, and parents divorced in junior school, experienced domestic violence by his father in the childhood, living with grandparents. He began to refuse to see parents from Grade One in High school, with sleep disorders at the same time (insomnia or morning reversal, early wake up, many dreams). After admission in the collage he got psychological evaluation score 347 points in the SCL 90. Three subjects hang up last semester, and whole door hang up in this semester. During this winter vacation he refused to go home, and reflected the idea of suicide, suspected suicide. The first crisis intervention had been taken. At the beginning of the second year, the psychological crisis investigation had been started again because of his high risk of suicide. And so did the joint intervention treatment of home and school.

\section{INTERVENTION PROCESS AND METHODS}

This case is a more successful home-school cooperation work. With a accurate judgment and a timely intervention, all the persons in charge, such as the college leaders, psychological center teachers, class advisers etc, had faced difficulties and repaired home and school relationship.

\subsection{The First Crisis Intervention}

During the sophomore winter vacation, the psychological center teacher called one by one to check the psychological focus on the students' recent state. MO answered the phone in low voice weak and feebly," it has been two days since I went out, no money, no food, everyone forgot me. I want to end my life and have planned to commit suicide (cutting the wrists or jumping from a building or car accident)." After talking about the idea of suicide, Mo suddenly said goodbye to the teacher." Thank you, teacher, for receiving your call in the last time. Goodbye." Then the line was shut. In this crisis situation, the college immediately organized crisis intervention teams.

\subsubsection{Teamwork and Clear Division}

The psychological center teacher reported the situation to the deputy secretary of the college at the first time. Then the teacher communicated with MO by telephone, Wechat, QQ and other ways, and carried out emotional comfort and psychological first aid. The idea of suicide in a crisis situation is a normal response, but not the only way to help he deal with immediate emotions. At the same time, collecting relevant information and confirming the student's current physical condition and location are the most important thing. 
There were clear division and cooperation between the College deputy secretary and the class teacher. The class teacher provided the student's specific address in time. The teachers of the college prepared the related emergency material, and unified the various forces to look for the student himself according to the telephone information. The secretary reported to the Minister of Learning and Industry, and he reported to the Head of the college in charge of the student's work. They all went to the scene.

The police also was called and provided crisis intervention support if necessary.

At the mean time the class teacher contacted his Guardian (parents) and requested them to the scene.

\subsubsection{Home-school Cooperation and School-medical Integration}

During the journey of the parents to school, the teachers communicated with the parents, expecially his mother, popularizing the emergency knowledge and the psychological communication skills, for preventing parents from not understanding or provoking MO so as to play a counterproductive role in rescue. After arriving at school, the parents took Mo away avoiding loneliness, and accompanied him with care and comfort during holidays.

In view of the serious crisis, with the help of hospital psychiatry diagnosis the teachers referraled him in time to prevent the event to be worsen. In this case, the teachers made a consultation with the parents off hand, referraled the student to medical institutions, and assisted with third-party professional forces successfully.

\subsection{The Second Crisis Intervention}

After the winter vocation, students returned school. During the psychological screening Mo entered the vision of teachers again. The fact was that a violent family conflict broke out after the first crisis intervention. However, in the later concern, the college follow-up evaluation found that the parents did not fulfill the responsibility of escort, and Mo lived outside school without authorization. After returning home for a week Mo shielded parents, only to maintain telephone contact with grandma, and stayed alone in the rental house for the New year. With the line of the psychological teacher Mo expressed a growing sense of negativity, despair, and in the words of the end of life again. "I will leave there alone in the near future...... To a place nobody knows... Ask for an answer... Not coming back ". The parents knew nothing about this except the grandparents, who knew he was in dangerous but can not have any idea to control the situation. Negative laissez-faire in her mind lead to the worst result. The communication also found that the parents thought that the teachers and the doctors made a fuss, and after the holiday they did not follow the doctor's advice for any psychotherapy. In this case, the teachers decided to intervene for the second time to help the student and save the families.

\subsubsection{To Visit the Family at That Very Night, And the True Care Awaked the Truth Consciousness}

In the second crisis intervention, after a deep discussion the teachers realized that parents had cognitive bias in the current situation of Mo. If they did so, they would only intensify the student negative emotions and not play a protective role. At the same time, parents showed obvious boredom and refused to come to school for further communication. Someone even thought that the problem of Mo was a fuss of the teacher, and also the doctor taking the opportunity to circle money and ignoring medical ethics. Considering the information of "the father had taken domestic violence to the mother and son, the mother called for the police because of his disobedient behavior. Refuse to see parents for many years. Live lonely. Do not believe anyone. Have no root" and so on, the psychological teachers judged that the student's heart knot lay in the family.

To save MO, must to repair the work of parents. Again, the college set up crisis a intervention team to visit MO families overnight. Because the family was divorced, the team was divided into two groups. One is composed of the head of the student work department, the director of the psychological center, the class teacher, working with the father and the grandparents. And the other is composed of psychological counsellor and deputy secretaries of the college who were familiar with MO, working with the mother. Through a few hours of patient communication, the family felt the sincerity of the college, realized the seriousness of the problem and the terrible consequences that inaction might bring, and decided to take the student to follow the doctor's advice and carry out a hospitalization. The team helped the families to contact the hospital and urge the student to take medicine.

\subsubsection{To Set the Facts and Reason in Very Patient, and To Go Through the Formalities of Suspension}

During the communication, the parents had strong resistance to the problem of suspension of schooling. From the perspective of his mental health development and medication care, the psychological teachers explained the necessity and significance of the suspension, and informed them of the relevant provisions from the Mental Health Law and the 
treatment suggestions. After knowing the student learning reports, psychological evaluation and diagnosis results, doctors' advice, his QQ space of negative speech, and the dispositions of his class absenteeism and of his disciplinary punishment, the parents understood the performance of Mo in the college, agreed with the teachers' sincere advice, and went through the suspension procedures.

\subsection{Post-tracking Measures}

When the suspension began, the teachers kept close contact with Mo and their families (parents and grandparents), recommended psychological self-help books for him, and urged them to use drugs and exercise regularly. Meanwhile psychological teachers made several consultations between Mo and his mother to ease the parent-child relationship.

\section{SUMMARIES AND REFLECTION}

\subsection{Time of Crisis Intervention}

The prime intervention time for cases is 24-72 hours after the crisis time, but in school work, it is often too late to intervene when the crisis occurs (Song Qiuyun, 2019). Especially for family problems, emotional problems caused by psychological crisis events, crisis intervention should be taken from the beginning of the school. In this case, the crisis intervention of $\mathrm{MO}$ is timely and effective, which is closely related to the concept of "early evaluation" and "long pursuit" adopted by the college.

\subsubsection{Early Assessment}

At the beginning of school enrolment, the school included Mo in the "medical attention" level according to the results of its psychological evaluation, and conducted quick psychological interviews to understand their family background and growth history (Han Xiu, 2017), focusing on collecting information on their self-injury suicide experience and campus bullying, domestic violence, inter-generational support, parents' marital status, and so on. According to these circumstances, they were documented, included in the crisis archives, and identified students with high suicidal tendency in advance.

\subsubsection{Long Tracking}

The school psychological center carries on the psychological appraisal at least three times every semester. Before the students return to school, the psychological evaluation of all the students to understand their holiday situation (Jl Wenze, etc, 2019)). In the middle of the semester, the students with psychological problems were investigated for crisis, academic, interpersonal and school performance. At the end of the semester, the crisis check will be taken before and after the holiday. A long-tracking method of work for psychological teachers provided a large number of the information of Mo, to help schools intervene timely and promptly.

\subsection{The Practical Dilemma of Home-school Interventions}

Home-school intervention is an effective method to help students grow up(Yan Ling, 2020), but in the process of crisis intervention, parents' false cognition and other factors often become the practical obstacle of home-school cooperation. Most parents think that after sending their children to college, the school needs to take full responsibility for the children, and the children's problems have nothing to do with the parents, and the management of the school is improper. As a result, the relationship between home and school is not conducive to the improvement of solving the problem. At the same time, parents often lack professional psychological knowledge, do not know enough about the seriousness of their children's psychological problems, or think that their children's psychological problems are developmental problems, and do not need parents to deal with or treat them(Myer A,etc, 2013). In addition, communication between schools and parents is not smooth or inadequate.

\section{CONCLUSION}

In the process of crisis intervention, we should pay attention to the practical dilemma of home-school cooperation. Work with parents in time, and work with hospitals and police when necessary (Xu Zhenhong, 2018). Communication with parents is to start from "legal theory "," pathology "," reason" and other aspects, to provide detailed and reliable student information.Patient. Sincere. Resolute (Wuran, etc, 2017). In this case, the school rushed thousands of miles to the hometown of MO, effectively guide them, can obtain their trust and cooperation, timely resolve the crisis. However, there are still recurrent problems such as parents not to accompany the reading responsibility. In the later period, therefore, we should maintain vigilance in the cooperation between home and school, keep communication open, and reduce the probability of parents rekindling and being careless.

\section{ACKNOWLEDGMENT}

This research was financially supported by the high-quality Students work project Foundation in Hubei province. Item number: 2019 XGJPX3022. 


\section{REFERENCES}

[1] Yan Ling (2020). Research on the Strategy of Home-school Cooperation in Precision Support Work of Colleges Based on Psychological Quality of the Students. 6th Annual International Conference on Social Science and Contemporary Humanity Development.121-123

[2] Xu Zhenhong (2018). Promoting home-school cooperation in psychological intervention with the model of Satya. Journal of Hefei normal University (2):82-85.

[3] Han Xiu (2017). Exploration and practice of psychological crisis intervention in schools-A probe into several cases of psychological crisis intervention. Mental health education in primary and secondary schools (20):12-15.
[4] Song Qiuyun (2019). Reflections on the communication between home and school in the psychological crisis of colleges and Universities [J]. Journal of Hunan University of Science and Engineering, 40(03), 54-55

[5] JI Wenze, TANG Linxia. (2019) Mental Crisis Intervention in Universities: Practice and Reflections[J].Journal of Higher Education Research,42(03),53-58

[6] Myer, Lewis S. (2013). James K.The introduction of a task model for crisis intervention [J]. Mental Health Counsel, (2):95-107.

[7] Wuran, Wang Jingyu, Chen jiangyuan (2017).Difficulties and Countermeasures of home school communication in college psychological crisis intervention [J]. Chin J Sch Health, January, 38(1):106-108 